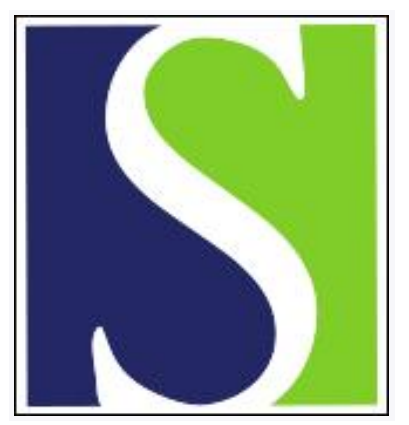

Scand J Work Environ Health 2003;29(3):220-229

https://doi.org/10.5271/sjweh.725

Issue date: Jun 2003

Meta-analysis of studies of occupational exposure to vinyl chloride in relation to cancer mortality

by Boffetta P, Matisane L, Mundt KA, Dell LD

Affiliation: Unit of Environmental Cancer Epidemiology, International Agency for Research on Cancer, 150 cours Albert-Thomas, 69008 Lyon, France. boffetta@iarc.fr

The following articles refer to this text: 2005;31(3):233-235;

2005;31(3):236

Key terms: angiosarcoma of the liver; brain cancer; cancer mortality; hematopoietic neoplasms; liver cancer; lung cancer; meta-analysis; occupational exposure; vinyl chloride

This article in PubMed: www.ncbi.nlm.nih.gov/pubmed/12828392 


\title{
Meta-analysis of studies of occupational exposure to vinyl chloride in relation to cancer mortality
}

\author{
by Paolo Boffetta, MD, ${ }^{1,2}$ Linda Matisane, MD, ${ }^{1,3}$ Kenneth A Mundt, PhD, ${ }^{4,5}$ Linda D Dell, MS ${ }^{4}$
}

\begin{abstract}
Boffetta P, Matisane L, Mundt KA, Dell LD. Meta-analysis of studies of occupational exposure to vinyl chloride in relation to cancer mortality. Scand J Work Environ Health 2003;29(3):220-229.
\end{abstract}

\begin{abstract}
Objective A meta-analysis was made of studies addressing occupational exposure to vinyl chloride in relation to cancer mortality.

Methods Two recently updated multicenter cohort studies and six smaller studies were identified. For selected neoplasms, standardized mortality ratios (SMR) and 95\% confidence intervals (95\% CI) were abstracted (or calculated from raw data). In cases of lack of heterogeneity (P-value $\geq 0.01$ ), meta-analyses were conducted using a random-effects model.

Results With SMR values ranging from 1.63 to 57.1 , all six studies for which these ratios could be obtained suggested an increased risk of liver cancer. For four of these studies, excesses persisted when known cases of angiosarcoma of the liver (ASL) were excluded. The meta-SMR for liver cancers other than ASL (based on the 2 large cohorts) was 1.35 (95\% CI 1.04-1.77). The meta-SMR for lung cancer was 0.90 (95\% CI 0.77-1.00, based on 5 studies), although higher SMR values were reported in early studies. The meta-SMR for brain cancer, based on 5 studies, was 1.26 (95\% CI 0.98-1.62). For soft tissue sarcomas, the meta-SMR based on 4 studies was 2.52 (95\% CI 1.56-4.07). The meta-SMR for lymphatic and hematopoietic neoplasms in the 2 large studies was 0.90 (95\% CI 0.75-1.01), although 3 of the smaller studies reported significant excesses.

Conclusions Apart from the known risk of ASL, workers exposed to vinyl chloride may experience an increased risk of hepatocellular carcinoma and soft-tissue sarcoma; however, these results may have been influenced by the underdiagnosis of true ASL. Increased mortality from lung and brain cancers and from lymphatic and hematopoietic neoplasms cannot be excluded; mortality from other neoplasms does not appear to be increased.
\end{abstract}

Key terms angiosarcoma of the liver, brain cancer, hematopoietic neoplasms, liver cancer, lung cancer, occupational exposure.

Vinyl chloride is a monomer used to produce polyvinyl chloride, a widely used plastic. It has been classified by the International Agency for Research on Cancer (IARC) as a group 1 carcinogen, with sufficient evidence of carcinogenicity in humans (1). To date, the only cancer that has clearly been associated with vinyl chloride exposure is angiosarcoma of the liver. In addition, neoplasms of the liver other than angiosarcoma, malignancies of the lung, brain and skin, and neoplasms of the lymphatic and hematopoietic system have been reported in excess in studies of vinyl chloride exposure (1-3).

Two large, multicenter epidemiologic studies of workers exposed to vinyl chloride have been reported recently (4-5). Their results are also available as detailed reports (6-7). These studies combine populations of exposed workers included in previous investigations and extend the follow-up. Six additional, smaller studies of populations not included in either of the two multicenter studies have been reported. Given the multiplicity

International Agency for Research on Cancer, Lyon, France.

Department of Medical Epidemiology, Karolinska Institutet, Stockholm, Sweden.

Institute of Occupational and Environmental Health, Medical Academy of Latvia, Riga, Latvia.

Applied Epidemiology, Inc, Amherst, Massachusetts, United States.

Center for Health Policy and Research, University of Massachusetts Medical School, Worcester, Massachusetts, United States.

Reprint requests to: Dr Paolo Boffetta, Unit of Environmental Cancer Epidemiology, International Agency for Research on Cancer, 150 cours Albert-Thomas, 69008 Lyon, France. [E-mail: boffetta@iarc.fr] 
of reports on several populations exposed to vinyl chloride and the heterogeneity of the results, we considered it useful to review the available evidence systematically, to combine formally the study results, and to discuss the reasons for the heterogeneity of the results. Using the results of these eight studies, we therefore present meta-analyses of cancer mortality risk among cohorts exposed to vinyl chloride, with the aims of formally assessing the heterogeneity of the results among available studies and of providing precise risk estimates by pooling study-specific results.

We focused on cohorts with exposure to vinyl chloride in monomer production and in polymerization, as these processes are presumed to represent the predominant exposure of vinyl chloride workers. However, workers may have also been exposed to ethylene dichloride, polyvinyl chloride dust, fillers, colorants, plasticizers and other additives, asbestos, and other potentially hazardous agents. Unfortunately, the published studies had not been able to measure exposure to vinyl chloride monomer or any other occupational exposure directly. Furthermore, exposures to other cancer risk factors, such as tobacco smoking, had not been measured in the source studies, and some level of confounding may have resulted for cancers related to these factors, especially if they were associated with employment in this industry.

\section{Subjects and methods}

Using Medline, we searched the peer-reviewed medical literature, through June 2002, for data on cancer mortality or morbidity associated with exposure to vinyl chloride. We identified eight independent studies (table 1).

Two of the studies selected for the meta-analysis (4, 5) were multicenter investigations including, or overlapping with, populations studied by other authors. The European multicenter study $(5,14)$ included most of the persons previously studied in the United Kingdom (15, $16)$, Norway $(17,18)$, Italy $(19,20)$, and Sweden $(21-$ 23), but the populations described in national reports did not completely overlap with those in the large multicenter study, due to different entry criteria (table 2). Therefore, the results of the individual studies could not be included in a meta-analysis. Their overlap with the multicenter study was so substantial that the observations could not be considered independent, and only results from the multicenter studies were used in the meta-analyses.

In the United States, the cohort initially studied by Tabershaw \& Gaffey (24), in which the association between vinyl chloride and angiosarcoma of the liver was first demonstrated, was subsequently expanded to

Table 1. Independent studies of cancer among vinyl chloride workers.

\begin{tabular}{|c|c|c|c|c|c|c|}
\hline Study & Countries & Plants (N) & Workers (N) & Entry criteria & Follow-up & Person-years \\
\hline Ward et al, 2001 (5) & $\begin{array}{l}\text { Italy, Sweden, } \\
\text { Norway, United Kingdom }\end{array}$ & 19 & 12700 & $\begin{array}{l}\text { One-year employment in exposed jobs, } \\
1955-1986\end{array}$ & $1955-1997$ & 324706 \\
\hline Mundt et al, 2000 (4) & United States, Canada & 37 & 10109 & $\begin{array}{l}\text { One-year employment in exposed jobs, } \\
1942-1972\end{array}$ & 1942-1995 & 316520 \\
\hline Smulevich et al, 1988 (8) & Former Soviet Union & 1 & 3232 & One-month employment, 1939-1977 & 1939-1977 & 43216 \\
\hline Laplanche et al, 1992 (9) & France & 12 & 1100 & Present in 1981 & $?-1988$ & 8299 \\
\hline Theriault \& Allard, 1981 (10) & Canada & 1 & 451 & Employment in 1948-1972 & 1948-1977 & 10192 \\
\hline Weber et al, 1981 (11) & Germany & $\mathrm{n} / \mathrm{a}$ & 7021 & Not specified & $?-1974$ & 73734 \\
\hline Huang, 1996 (12) & China & 14 & 5958 & Employment in 1958-1981 & $1958-1981$ & 67358 \\
\hline Wong et al, 2002 (13) & Taiwan & 6 & 3239 & Employment in 1950-1992 & $1985-1997$ & 40557 \\
\hline
\end{tabular}

Table 2. Study populations included in the European multicenter cohort (5).

\begin{tabular}{llrrr}
\hline Study & Countries & Workers (N) & Years of employment & Years of follow-up \\
\hline Simonato et al, 1991 (14) & Italy, Sweden, Norway, United Kingdom & 12706 & $1945-1986$ & $1955-1986$ \\
Langard et al, $2000(18)$ & Norway & 428 & $1950-1969$ & $1953-1993$ \\
Heldaas et al, 1984 (17) & Norway & 454 & $1950-1969$ & $1953-1979$ \\
Pirastu et al, 1998 (20) & Italy & 1259 & $1953-1985$ & $1953-1997$ \\
Belli et al, 1987 (19) & Italy & 1256 & $?-1984$ & $1953-1984$ \\
Hagmar et al, 1990 (23) & Sweden & 2031 & $1945-1980$ & $1961-1985$ \\
Molina et al, 1981 (22) & Sweden & 1970 & $1945-1974$ & $1961-1976$ \\
Byren et al, 1976 (21) & Sweden & 771 & $?-1974$ & $?-1974$ \\
Jones et al, 1988 (16) & United Kingdom & 5560 & $1940-1974$ & $?-1984$ \\
Fox \& Collier, 1977 (15) & United Kingdom & 7561 & $1940-1974$ & $1940-1974$ \\
\hline
\end{tabular}


include additional populations and formed the North American multicenter cohort (25), which was later updated through 1982 (26). Several publications have been based on completely or partially overlapping populations (table 3). Most recently, this cohort was updated, including the identification and elimination of duplicate employees and the restoration of a substantial number of cohort members previously lost to follow-up (4). Only results from this last multicenter study are included in the meta-analysis.

The study from Taiwan (13) was an update and expansion of a previous study comparing morbidity due to liver conditions among vinyl chloride workers with that of a group of workers manufacturing optical equipment and motorcycles (34).

For each of the remaining studies, we abstracted numbers of observed and expected deaths for all malignant neoplasms and, except for the study by Laplanche et al (9), for specific neoplasms, standardized mortality ratios (SMR), and $95 \%$ confidence intervals (95\% CI). For a few categories of cause of death that were not reported but for which data were available, we calculated the SMR or $95 \%$ CI values from the raw data. Before pooling any results, we assessed the heterogeneity of the study-specific results with a statistical test (35). When the P-value of the test for heterogeneity was $\geq 0.01$, we concluded that the study-specific results were adequately similar (ie, lack of evidence that the results were dissimilar or heterogeneous), we conducted a meta-analysis based on random-effects modeling, and we calculated meta-SMR values and their $95 \%$ CI.

As it was known that vinyl chloride exposure is a cause of liver angiosarcoma, we aimed at disentangling the mortality related to this neoplasm from that related to other types of liver cancer (mainly hepatocellular carcinoma). However, only for the European multicenter study were detailed results by histology reported. We therefore excluded the deaths reported to be from angiosarcoma from the total number of deaths from primary liver cancers, without modifying the number of expected deaths. This approach was justified because, out of all primary liver cancers, less than $1 \%$ are angiosarcomas, in both European (36) and American (37) populations. A meta-analysis for angiosarcoma of the liver was not conducted as relevant SMR values were difficult to estimate due to the extreme rarity of the disease in the general population.

In several studies, results were presented for indirect indicators of exposure to vinyl chloride, such as the duration of employment and latency. We did not attempt to perform a meta-analysis according to such indicators because of the heterogeneity among them. However, we used the study-specific evidence in the discussion of our results. Only in the European multicenter study, a quantitative estimate of vinyl chloride exposure was available, which was based on job-, plant- and calendar-period-specific exposure matrices (38).

\section{Results}

We report the results of the individual studies in table 4 and the results of the meta-analyses in table 5. The meta-analyses were based (depending on the availability of data and the heterogeneity of results for specific outcomes of interest) on a maximum of 43810 workers included in eight studies, among whom 2079 cancer deaths occurred. This total of all cancer deaths is very close to what would be expected in a comparable unexposed population (SMR 1.01, 95\% CI 0.95-1.08). The two multicenter studies contributed $86 \%$ of these cancer deaths and therefore tended to drive the results of the meta-analyses.

Table 3. Study populations included in the American multicenter cohort study (4).

\begin{tabular}{|c|c|c|c|c|c|}
\hline Study & Plants (N) & Overlap & Workers (N) & Years of employment & Years of follow-up \\
\hline Wong et al, 1991 (26) & 37 & Complete & 10173 & 1942-1972 & 1942-1982 \\
\hline Cooper, 1981 (25) & 37 & Complete & 10173 & 1942-1972 & 1942-1972 \\
\hline Tabershaw \& Gaffey, 1974 (24) & 33 & Complete & 8384 & $1942-1972$ & 1942-1972 \\
\hline Dahar et al, 1988 (27) & 1 & Partial & 594 & $1942-1960$ & 1942-1982 \\
\hline Ott et al, 1975 (28) & 1 & Partial & 594 & $1942-1960$ & $1942-1973$ \\
\hline Buffler et al, 1979 (29) & 1 & Partial & 464 & $1948-1975$ & $1948-1975$ \\
\hline Wu et al, 1989 (30) & 1 & Partial & 3635 & $1942-1973$ & $1942-1986$ \\
\hline Waxweiler et al, 1976 (31) & 4 & Complete & 1294 & $1942-1973$ & $1942-1973$ \\
\hline Nicholson et al, 1975 (32) & 1 & Complete & 257 & $1946-1973$ & $1956-1974$ \\
\hline Monson et al, 1974 (33) & 2 & Complete & $161^{a}$ & .. & $1947-1973$ \\
\hline
\end{tabular}

a Deceased workers 
Table 4. Mortality by cause. ( $\mathrm{N}=$ number of observed deaths, $\mathrm{SMR}=$ standardized mortality ratio, $95 \% \mathrm{Cl}=95 \%$ confidence interval, $\mathrm{CNS}=$ central nervous system, $\mathrm{NHL}=$ non-Hodgkin's lymphoma)

\begin{tabular}{|c|c|c|c|c|c|c|c|c|c|c|c|c|c|c|c|c|c|c|c|c|c|c|c|c|}
\hline \multirow[t]{2}{*}{ Cause of death ${ }^{\mathrm{a}}$} & \multicolumn{3}{|c|}{ Ward et al, 2001 (5) } & \multicolumn{3}{|c|}{$\begin{array}{l}\text { Mundt et al, } \\
2000 \text { (4) }\end{array}$} & \multicolumn{3}{|c|}{$\begin{array}{l}\text { Laplanche et al, } \\
1992(9)^{\text {b }}\end{array}$} & \multicolumn{3}{|c|}{$\begin{array}{l}\text { Smulevich et al, } \\
1988 \text { (8) }\end{array}$} & \multicolumn{3}{|c|}{$\begin{array}{l}\text { Theriault \& Allard } \\
1981 \text { (10) }\end{array}$} & \multicolumn{3}{|c|}{$\begin{array}{l}\text { Weber et al, } \\
1981 \text { (11) }\end{array}$} & \multicolumn{3}{|c|}{ Huang, 1996 (12) } & \multicolumn{3}{|c|}{$\begin{array}{l}\text { Wong et al, } \\
2002(13)\end{array}$} \\
\hline & $\mathrm{N}$ & SMR & $95 \% \mathrm{Cl}$ & $\mathrm{N}$ & SMR & $95 \% \mathrm{Cl}$ & $\mathrm{N}$ & SMR & $95 \% \mathrm{Cl}$ & $\mathrm{N}$ & SMR & $95 \% \mathrm{Cl}$ & $\mathrm{N}$ & SMR & $95 \% \mathrm{Cl}$ & $\mathrm{N}$ & SMP & $95 \% \mathrm{Cl}$ & $\mathrm{N}$ & SMR & $95 \% \mathrm{Cl}$ & $\mathrm{N}$ & SMR & $95 \% \mathrm{Cl}$ \\
\hline $\begin{array}{l}\text { All malignancies } \\
(140-208)\end{array}$ & 883 & 0.99 & $0.93-1.06$ & 895 & 0.96 & $0.90-1.02$ & 38 & 1.3 & $0.8-2.1$ & 63 & 1.07 & $0.82-1.36^{c}$ & 20 & 1.22 & $0.75-1.89^{c}$ & 94 & 1.12 & $0.91-1.37^{c}$ & $29^{c}$ & $0.85^{c}$ & $0.57-1.23^{c}$ & 57 & 1.30 & $0.99-1.69$ \\
\hline $\begin{array}{l}\text { Liver cancer } \\
\text { (155) }\end{array}$ & 53 & 2.40 & $1.80-3.14$ & $80^{d}$ & 3.59 & $2.84-4.46$ & 6 &.. & .. & - & . & . & 8 & 57.1 & $24.6-113^{c}$ & 12 & 15.2 & $7.86-26.6^{c}$ & $10^{\mathrm{e}}$ & 1.36 & $0.65-2.51^{c}$ & 25 & 1.78 & $1.15-2.62$ \\
\hline $\begin{array}{l}\text { Liver, except } \\
\text { angiosarcoma } \\
\text { of the liver }^{\dagger}\end{array}$ & 28 & 1.27 & $0.84-1.834$ & $40^{c, d}$ & $1.8^{c}$ & $1.3-2.5^{c}$ & 3 &.. & .. & - & . & . & - & . & . & 8 & 10.1 & $4.37-20.0^{c}$ & c.. &.$\cdot$ & .. & 25 & 1.78 & $1.15-2.62$ \\
\hline $\begin{array}{l}\text { Lung cancer } \\
\text { (162) }\end{array}$ & 272 & 0.95 & $0.84-1.07$ & 303 & 0.82 & $0.73-0.92$ & 8 & .. &.. & 17 & 1.39 & $0.81-2.23^{c}$ & $2^{g}$ & 0.34 & $0.04-1.25^{c}$ &. &.. &.. & 5 &.. &.. & $4^{\mathrm{h}}$ & 0.59 & $0.16-1.52$ \\
\hline $\begin{array}{l}\text { Soft-tissue } \\
\text { sarcoma (171) }\end{array}$ & 6 & 1.89 & $0.69-4.11$ & 12 & 2.70 & $1.39-4.72$ & 1 & .. &.. & $1^{\text {h }}$ & 1.43 & $0.02-7.95^{c}$ & $2^{i}$ & 5.26 & $0.59-19.0^{c}$ & .. &.$\cdot$ &.$\cdot$ & .. &.. &.. & .. & .. &.. \\
\hline $\begin{array}{l}\text { Skin cancer and } \\
\text { melanoma (172-173) }\end{array}$ & 20 & 1.69 & $1.03-2.60$ & 12 & 0.64 & $0.33-1.12$ & 3 &.. &.. & 1 & 2.00 & $0.03-11.1^{c}$ & - & [see s & soft tissue] & .. &.$\cdot$ &.$\cdot$ & .. &.. &.. & .. & .. & .. \\
\hline $\begin{array}{l}\text { Brain and CNS } \\
\text { cancer (191-192) }\end{array}$ & 24 & 0.93 & $0.60-1.39$ & 36 & 1.42 & $1.00-1.97$ &.. &.. &.. & 4 & 1.54 & $0.41-3.94^{c}$ & - & .. &.. & $2^{i}$ & 1.62 & $0.18-5.85^{c}$ & $=1$ &.. &.. & $2^{i}$ & $2.86^{c}$ & $0.57-9.16^{c}$ \\
\hline $\begin{array}{l}\text { Neoplasms of lymphatic } \\
\text { and hematopoietic } \\
\text { system (200-208) }\end{array}$ & 62 & 0.94 & $0.72-1.21$ & 71 & 0.86 & $0.67-1.08$ & 1 &.. &.. & 10 & 4.55 & $2.81-8.36^{c}$ & 1 & 0.60 & $0.01-3.33^{c}$ & 15 & 2.14 & $1.12-3.53^{c}$ & $=1$ &.. &.. & 7 & 2.71 & $1.09-5.60$ \\
\hline $\begin{array}{l}\text { NHL } \\
\text { and multiple myeloma } \\
(200,202,203)\end{array}$ & $33^{c}$ & $0.98^{\circ}$ & $0.67-1.37^{c}$ & $37^{\circ}$ & $0.86^{c}$ & c $0.60-1.18^{c}$ & c .. &.. &.. & $5^{k}$ & 4.17 & $1.34-9.72^{c}$ & - & .. &.. & .. &.. &.. & - &.. &.. & .. & .. &.. \\
\hline $\begin{array}{l}\text { Hodgkin's } \\
\text { lymphoma (201) }\end{array}$ & 7 & 1.03 & $0.41-2.12$ & 3 & 0.44 & $0.09-1.29$ &.. &.. &.. & & $\begin{array}{l}\text { [see N } \\
\text { myelo }\end{array}$ & $\begin{array}{l}\text { NHL and } \\
\text { oma] }\end{array}$ & - & .. &.. & .. &.. &.. & - &.. &.. & .. & .. &.. \\
\hline $\begin{array}{l}\text { Leukemia } \\
\text { (204-208) }\end{array}$ & 22 & 0.87 & $0.54-1.31$ & 31 & 0.94 & $0.64-1.34$ & .. & .. &.. & 5 & 5.00 & $1.61-11.7^{c}$ & - & .. & .. & .. &.. &.. & 1 &.. & .. & .. & .. & .. \\
\hline
\end{tabular}

a Codes of the International Classification of Diseases (9th revision) in parentheses.

b Cancer incidence comparison with workers from the same plant but unexposed to vinyl cloride.

c Derived from raw data.

${ }^{d}$ Liver and biliary tract (155-156)

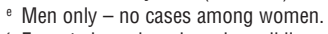

${ }^{t}$ Expected numbers based on all liver cancers.

9 Respiratory organs (160-163).

${ }^{h}$ Bone and soft tissue (170-171).

Bone, soft tissue and skin (170-173).

i Brain (191).

k Lymphoma and multiple myeloma (200-203).

Table 5. Results of the meta-analysis. ${ }^{a}$ (SMR = standardized mortality ratio, $95 \% \mathrm{Cl}=95 \%$ confidence interval, $\mathrm{NHL}=$ non- $\mathrm{Hodgkin}$ 's lymphoma)

\begin{tabular}{|c|c|c|c|c|c|c|c|}
\hline \multirow[t]{2}{*}{ Causes of death ${ }^{b}$} & \multirow{2}{*}{$\begin{array}{l}\text { Number of } \\
\text { studies }\end{array}$} & \multicolumn{3}{|l|}{ All studies } & \multicolumn{3}{|c|}{ Two multicenter studies } \\
\hline & & $P$ value for heterogeneity & SMR & $95 \% \mathrm{Cl}$ & $P$ value for heterogeneity & SMR & $95 \% \mathrm{Cl}$ \\
\hline All malignancies (140-208) & 8 & 0.2 & 1.01 & $0.95-1.08$ & 0.5 & 0.97 & $0.93-1.02$ \\
\hline Liver (155) & 6 & $<0.001$ & . & . & 0.03 & 2.96 & $2.00-4.39$ \\
\hline Liver except angiosarcoma of the liver & 4 & $<0.001$ & . & . & 0.7 & 1.35 & $1.04-1.77$ \\
\hline Lung (162) & 5 & 0.1 & 0.90 & $0.77-1.06$ & 0.09 & 0.88 & $0.76-1.01$ \\
\hline Bone (170) & 2 & c & c & c & 0.9 & 1.15 & $0.52-2.53$ \\
\hline Soft tissue (171) & 4 & 0.7 & 2.52 & $1.56-4.07$ & 0.5 & 2.41 & $1.45-3.99$ \\
\hline Skin (172-173) & 3 & 0.05 & 1.11 & $0.49-2.54$ & 0.01 & 1.06 & $0.41-2.73$ \\
\hline Brain (191-192) & 5 & 0.4 & 1.26 & $0.98-1.62$ & 0.12 & 1.17 & $0.77-1.77$ \\
\hline Thyroid (193) & 2 & c & c & c & 0.9 & 1.41 & $0.49-4.00$ \\
\hline $\begin{array}{l}\text { Neoplasms of the lymphatic and } \\
\text { hematopoietic systems (200-208) }\end{array}$ & 6 & $<0.001$ & . & . & 0.6 & 0.90 & $0.75-1.07$ \\
\hline NHL, myeloma $(200,202,203)$ & 3 & 0.01 & 1.23 & $0.70-2.19$ & 0.6 & 0.91 & $0.71-1.17$ \\
\hline Hodgkin’s Iymphoma (201) & 2 & c & c & c & 0.3 & 0.80 & $0.37-1.71$ \\
\hline Leukemia (204-208) & 3 & 0.005 & . & . & 0.8 & 0.91 & $0.69-1.21$ \\
\hline
\end{tabular}

a The meta-analysis was performed when the P-value for heterogeneity was $\geq 0.01$.

${ }^{b}$ Codes of the International Classification of Diseases (9th revision) in parentheses.

c Only the results of two multicenter studies available; see the right side of the table. 


\section{Liver cancer}

The SMR of liver cancer was increased in all the available studies except the one from the former Soviet Union, which reported no deaths from this neoplasm. For the remaining studies, the SMR ranged from 1.36 to 57.1, and the results were too heterogeneous to be included in a meta-analysis. Out of the total 133 deaths that occurred from liver cancer in the two multicenter studies, 65 were known to be cases of angiosarcoma. The remaining 68 deaths included histologically confirmed hepatocellular carcinomas, liver cancers of other known histology, and primary liver cancers with an unspecified histology (possibly including angiosarcomas). When documented angiosarcoma deaths were excluded, and the expected numbers were not modified, the resulting pooled SMR was 1.35 (95\% CI 1.04-1.77).

Total liver cancer mortality was reported according to the duration of employment in three studies (figure 1). On one hand, in the two multicenter studies, the SMR was close to unity for workers employed up to 7 years, and a plateau was suggested (SMR between 6 and 7) for a duration of employment of more than 25 years. In the German study, on the other hand, the SMR increased steeply even for workers with less than 7 years of employment. A decrease in the SMR of total liver cancer mortality by year of first employment was found in both multicenter studies, and the patterns were remarkably

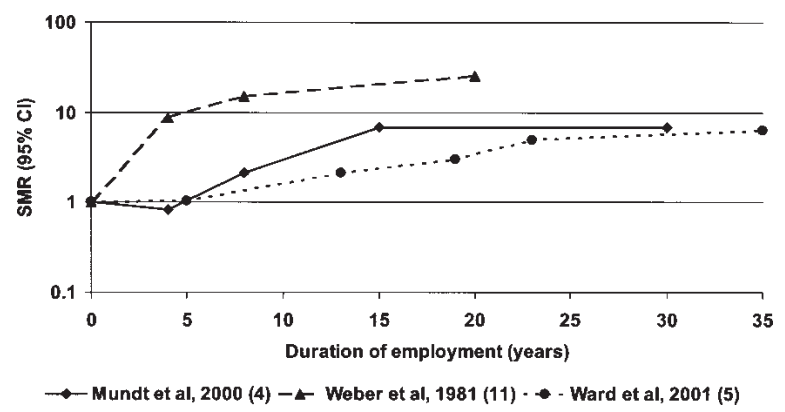

Figure 1. Standardized mortality ratio (SMR) of liver cancer by duration of employment.

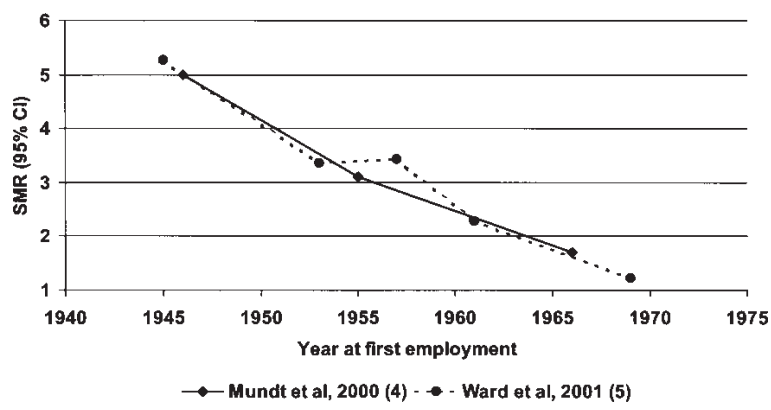

Figure 2. Standardized mortality ratio (SMR) of liver cancer by year of first employment. similar (figure 2). Neither study was adequate for a proper assessment of the SMR for workers first employed after 1975 in that the North American study did not include people first employed after 1972 and the European study had a small number of employees and an inadequate length of follow-up.

\section{Lung cancer}

The results on lung cancer were fairly heterogeneous. Decreased mortality was reported in four of five studies, and was statistically significant in the North American study (table 4). A nonsignificant increase in the SMR was reported in the study from the former Soviet Union. The meta-SMR was 0.90 (95\% CI 0.77-1.06). In neither of the two multicenter studies was there a suggestion of a trend with time since first exposure or duration of exposure (data not shown in detail).

\section{Soft-tissue sarcoma}

There were 22 deaths from soft-tissue sarcoma reported in the available studies. (In the studies from Canada and the former Soviet Union, the SMR values for soft-tissue sarcoma were reported in combination with other nosological groups, whereas in the Canadian study the two observed deaths were soft-tissue sarcomas.) The meta-SMR was 2.52 (95\% CI 1.56-4.07). Three of the six deaths coded as soft-tissue tumors in the European multicenter study were found to be cases of liver angiosarcoma whose primary site had been miscoded (5). However, in the North American study, only 4 of the 12 soft-tissue cancers were angiosarcomas with site not specified, and 7 others were specific soft-tissue cancers other than angiosarcoma.

\section{Skin cancer}

The results on mortality from skin cancer, including both melanoma and nonmelanoma cancer, were heterogeneous, but there was no indication of an increased risk (pooled SMR 1.11, 95\% CI 0.49-2.54). Among the two large studies, the European one generated a statistically significant positive SMR (which was largely due to an excess incidence in Norway), whereas the North American study suggested a moderate deficit that was not statistically significant.

\section{Brain cancer}

A total of 66 deaths from brain cancer was reported in four studies (meta-SMR $1.23,95 \%$ CI $0.95-1.58$ ). The increase in the meta-SMR was mainly due to the North American multicenter study, in which the excess of mortality was most apparent between 1970 and 1979, 
but not in subsequent years (4). In neither of the two large studies was a trend with duration of exposure suggested (figure 3).

\section{Cancer of the lymphatic and hematopoietic systems}

The results from six studies reporting malignancies of the lymphatic and hematopoietic systems were heterogeneous. When we restricted the analysis to the two multicenter cohorts, however, the heterogeneity was reduced and the meta-SMR was 0.90 (95\% CI 0.75-1.07). However, the studies from the former Soviet Union (8), Canada (10), and Taiwan (13) reported significantly increased mortality. We were able to break these data into three categories, comprising non-Hodgkin's lymphomas and multiple myeloma (ICD 200, 202, 203), Hodgkin's lymphoma (ICD 201), and leukemia (ICD 204-208). There was no indication of an increased SMR for any of these categories of neoplasms.

\section{Discussion}

Our study provided the most precise estimates of cancer risk among workers exposed to vinyl chloride. Furthermore, it provided direct evidence of agreement for most of the results of the two main studies. Among the original results of our meta-analysis, beyond what has been reported in the individual studies, is the evidence of (i) an increased risk of liver cancer after the exclusion of known deaths from angiosarcoma of the liver, (ii) a lack of increase in brain and lung cancer risk, and (iii) a possible increased risk of soft-tissue sarcoma.

None of the studies pointed out a significant increase in total mortality from malignancies. The total number of observed cancer deaths was essentially equal to that expected; thus the increase in risk of any specific cancer, most notably angiosarcoma of the liver and possibly liver cancer, was offset by deficits of deaths from other types of cancer. In most studies, a substantial and highly significant deficit of all nonmalignant causes of death has been noted, and this outcome is compatible with generally healthy working populations. This effect of selection of healthy persons for work on mortality is typically not seen for malignancies, especially with increased follow-up (39).

As expected, there was a strong indication of an increase in the SMR for primary liver cancer. As sufficient evidence exists for a causal relationship between occupational exposure to vinyl chloride and angiosarcoma of the liver, we focused our interest on other liver cancers by removing known angiosarcoma of the liver deaths from the analyses. We found a weak but statistically significant increase in the SMR of liver cancers

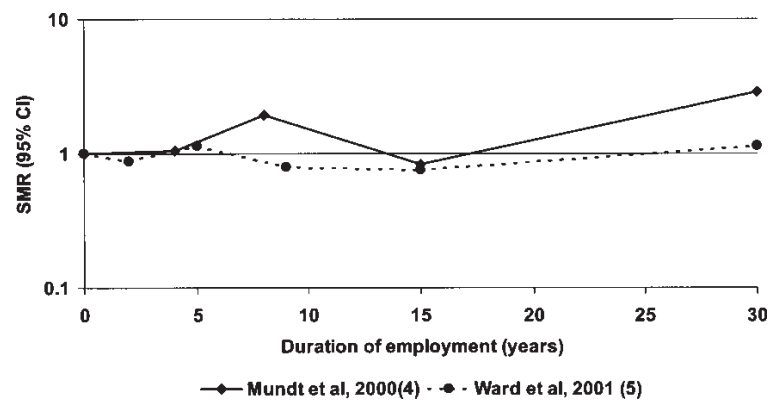

Figure 3. Standardized mortality ratio (SMR) of brain cancer by duration of employment.

other than angiosarcoma. However, it should be pointed out that the group of primary liver cancers other than angiosarcoma includes deaths without a histologically verified diagnosis. Some of these liver cancer deaths may have been cases of angiosarcoma, especially among deaths observed in early periods, when the diagnostic capability and the awareness of the relationship with vinyl chloride were poor. In this respect, it is worth noting that the SMR of this category was lower in the European multicenter study than in the North American one. In the former study, the authors performed a moredetailed review of cases of liver cancer than in the North American study. The notion of an increased risk of liver cancer other than angiosarcoma, on the other hand, is supported by the dose-response analysis performed in the European study, which suggested a trend in mortality from hepatocellular carcinoma (10 deaths) according to estimated cumulative exposure to vinyl chloride (5). Additional support comes from the results of the study from Taiwan (13). Out of 25 deaths from liver cancer, 9 had a pathologically or clinically confirmed hepatocellular carcinoma, while there were no confirmed cases of angiosarcoma of the liver. The carcinogenic effect of vinyl chloride on hepatocytes may involve a synergism with other causes of hepatocellular carcinoma, notably infection with hepatitis $B$ virus (HBV). Out of 16 cases of liver cancer in the study from Taiwan (13) with known HBV status, 15 were positive for the virus. Furthermore, in the three studies providing relevant results $(4,5,13)$, the mortality from liver cancer (excluding angiosarcoma of the liver) was almost completely offset by a corresponding decrease in mortality from liver cirrhosis, a finding suggesting that vinyl chloride enhances carcinogenesis in an otherwise chronically damaged liver.

Our results on soft-tissue sarcomas are consistent with the notion, suggested by earlier case reports (4042), that exposure to vinyl chloride may cause angiosarcoma or other sarcomas in organs other than the liver. The results of the North American multicenter study tended to support this theory, through the increased SMR for soft-tissue cancers and the identification of 
four deaths from sarcoma (not angiosarcoma) of specific organs other than the liver. However, this interpretation is challenged by the findings of the European multicenter study, which suggested that the increase in SMR was due to misclassification on the death certificates of a few cases involving angiosarcoma of the liver (5). Because of the rarity of these cancers, the difficulty in determining valid diagnoses from the cause of death mentioned on the death certificates, and a diminishing population of heavily exposed workers, it will be difficult to clarify this issue.

Despite some statistical heterogeneity, the results on lung cancer were fairly consistent in not showing an excess. These results are at odds with earlier data suggesting a positive association. Some of the populations in which increased mortality from lung cancer or an increased incidence of lung cancer was reported have been included in either the European multicenter study (17, 19, 23) or the North American one (29, 31). In figure 4, we have summarized the accumulating evidence on an association between lung cancer and vinyl chloride exposure by presenting the results of repeated meta-analyses conducted on the data reported up to each year between 1974 and 2002. Using the SMR available before 1987-1990, as well as the suggestion of a higher risk in some groups with longer durations of exposure and latency, one would have concluded that vinyl chloride workers may be at increased risk of lung cancer (2). Results published subsequently, mainly from the two multicenter studies $(14,26)$, did not confirm these findings. It should also be stressed that an increased mortality from lung cancer was reported among workers employed as packers and baggers in the European study (5).

The reasons for the decreased lung cancer mortality in the two largest cohorts are unclear. A probable explanation, however, is reduced tobacco consumption among vinyl chloride workers in comparison with the consumption of the general population. Data on the

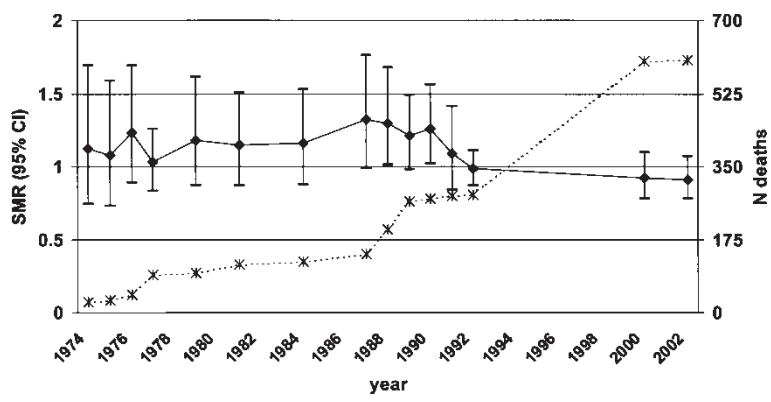

Figure 4. Cumulative meta-analysis of lung cancer-pooled standardized mortality ratios (SMR), with their 95\% confidence intervals (95\% $\mathrm{CI}$ [ [diamonds and bars, respectively] and the number of lung cancer deaths [stars] by year of publication of subsequent reports. smoking habits of a small proportion of workers from a Norwegian cohort, which was eventually included in the European multicenter study (17), suggest that the prevalence of tobacco smoking was slightly higher than in the national population and, accordingly, the SMR for lung cancer was increased in that cohort. In older polymerization facilities, where ambient exposures to vinyl chloride were likely to have been much higher and posed an explosion hazard, smoking would have been prohibited.

Brain cancer has been an object of interest in several studies. The results of the pooled analysis showed no statistically significant increase in mortality from brain cancer, although, among the cohort members employed the longest in both multicenter studies, elevated risks were noted. Because the etiology of brain cancers is poorly understood, and because exposure histories are unavailable, it is difficult to assess whether the workers for whom the excess mortality was noted had been exposed to other industrial risk factors.

The pooled analysis of mortality from malignancies of the lymphatic and hematopoietic system was limited by the heterogeneity of the study results. Data from the two largest studies showed no evidence of an association with vinyl chloride exposure. This lack of an association also applied to specific groups of neoplasms (lymphomas, multiple myeloma, and leukemia). However, the results from three smaller studies $(8,10,13)$ were positive, with limited information on specific neoplasms within this group. The reasons for the heterogeneity of the results are unclear, and reporting bias may have played a role. Taken together, the available results did not provide strong support for an association between vinyl chloride exposure and lymphatic and hematopoietic neoplasms, but a negative conclusion is premature.

Our combined analysis suffers from several limitations. First, the assessment of exposure to vinyl chloride was, in most studies, limited to data on employment in vinyl chloride production, and the duration of employment was the only quantitative exposure indicator. The variability in the probability and level of exposure among production workers is likely to have attenuated any association between vinyl chloride and cancer.

Second, SMR values and similar measures of association based on indirect standardization depend on the age structure of the standard population. They may therefore not be fully comparable. However, if the different populations have similar age structures (as is likely to be the case for the European and North American vinyl chloride workers studied), the resulting bias is likely to be very small. However, the fact that mortality from all cancers was remarkably close to that expected in both studies may be an argument in favor of combining 
the results of at least these two studies. Furthermore, we adopted a random-effects model for our meta-analysis, which resulted in less precise combined estimates, to compensate for the possible effect of the difference in exposure assessment and standard populations among the studies, in addition to potential problems with the comparability of SMR values.

Third, the application of a statistical test for heterogeneity favors the combination of imprecise results usually based on fewer observed outcomes, as it is more difficult to reject the null hypothesis under these circumstances. Conversely, results based on larger numbers are usually more precise, and the test for heterogeneity is more likely to generate a small P-value, even if the difference in point estimates is small. This is an inherent limitation of the methodology, and it calls for careful interpretation, with more attention paid to the individual estimates than to the combined results. However, in the case of liver cancer, the results were heterogeneous, but, for all but one study, they provided evidence of an increased risk.

In our opinion, the available evidence on the carcinogenicity of vinyl chloride has four characteristics that make it an interesting case in occupational cancer research. In the first place, the agent is a strong risk factor for a very rare cancer-angiosarcoma of the liver. In this case, the excess incidence was so striking that it was "easily" detected by astute clinicians, and strong evidence was already available in 1975 on the basis of case reports $(24,43)$. The relationship between vinyl chloride exposure and angiosarcoma of the liver is also one of the most specific industrial chemical carcinogenic associations commonly seen, with no other known risk factors (and therefore no potential confounders).

Second, as with many chemical exposures, the early epidemiologic evaluations provided suggestive evidence for additional targets of vinyl chloride carcinogenicity, namely, lung cancer. However, the early results were not confirmed by subsequent investigations, which had greater statistical power and better exposure information. Credible reviews conducted in the 1980s concluded, on the basis of the evidence available at that time, that a causal association was plausible in the case of lung cancer $(1,2)$. These examples speak for the need to confirm reports of small excesses of common cancers. In the case of lung cancer among vinyl chloride workers, the early positive results might have been attributable to either confounding by other occupational exposures or confounding by extra-occupational exposure (most likely tobacco smoking) or to chance.

The third point deals with the slow emergence of the evidence that malignancies other than liver angiosarcoma may be caused by exposure to vinyl chloride. This may particularly be the case for hepatocellular carcinoma. Small excesses of rare tumors with long latency periods need therefore to be assessed with long followups. However, while the meta-analysis supports a small excess of liver cancers apart from angiosarcoma and other studies and evidence exists that supports the hypothesis, clearer evidence is still needed. For a large proportion of the liver cancer deaths, it remains unclear whether they represent under-ascertained angiosarcomas or not.

Fourth, the recent results on soft-tissue sarcoma of the two multicenter cohort studies argue for great care in the interpretion of results on rare tumors that may suffer from diagnostic misclassification. In the case of the European multicenter study, an overestimation of the SMR arose from the misclassification of liver angiosarcoma as sarcoma from other, or unspecified, organs. Given the rarity of soft-tissue sarcomas, and the relatively large number of liver angiosarcomas, a misclassification of $10 \%$ of the cases of this neoplasm was sufficient to generate a twofold increase in the estimated mortality from soft-tissue sarcoma. In the North American multicenter study, there was also evidence of misdiagnosed angiosarcomas coded as soft-tissue cancers; however, even after these cases were removed, there were 8 observed cases, against 4.4 expected, 7 of which had clear diagnoses other than angiosarcoma of the liver.

Therefore, also in the case of soft-tissue sarcoma, more evidence is required, and the diagnosis of reported deaths from these neoplasms should be subject to careful investigation. The present evidence points towards a possible effect of vinyl chloride exposure on neoplasms other than liver angiosarcoma.

It is unlikely that additional, large cohorts of workers exposed to high levels of this agent will be enrolled in the future, mainly due to the drastic decrease in exposure levels that took place in the vinyl chloride industry after 1974, following the publication of convincing evidence of carcinogenic activity on the liver. Additional extension of the follow-up of existing multicenter studies may help to elucidate these issues; however, the maximum latency period for many, if not most, cancers is approaching, and additional cancers are more and more likely to reflect background and other risk factors other than vinyl chloride.

Large populations of vinyl chloride workers who experienced different levels of exposure are available in countries where occupational cohort studies are feasible, notably in Central and Eastern European countries. Such studies would provide additional information that would contribute to the elucidation of the main open questions on vinyl chloride carcinogenicity (effect on soft-tissue sarcoma, liver cancers other than angiosarcoma). The available cohort studies should be expanded to include workers employed only after the dramatic decrease in exposure levels, to investigate the risk of angiosarcoma at low doses.

Scand J Work Environ Health 2003, vol 29, no 3 
In addition, a very promising approach in cases of experimental and human angiosarcomas is the identification of a mutation in the p53 gene, which is relatively specific for vinyl chloride exposure $(44,45)$. There are sparse data on the analysis of p53 mutation in other tumors of exposed workers; results on hepatocellular carcinoma, however, are consistent with a carcinogenic effect (46). There is need for larger studies of p53 mutation in tumors, other than liver angiosarcoma, that appear in workers exposed to vinyl chloride.

\section{Acknowledgments}

Linda Matisane performed the analysis during a research training visit to the International Agency for Research on Cancer in Lyon, France, and was supported by a fellowship from the American Latvian Association. Special thanks go to Aina Galeja.

\section{References}

1. International Agency for Research on Cancer (IARC). Overall evaluations of carcinogenicity: an updating of IARC monographs, vol 1-42. Lyon: IARC; 1987. IARC monographs on the evaluation of the carcinogenic risk of chemicals to humans, suppl 7.

2. Doll R. Effects of exposure to vinyl chloride: an assessment of the evidence. Scand J Work Environ Health 1988;14:6178.

3. McLaughlin JK, Lipworth L. A critical review of the epidemiologic literature on health effects of occupational exposure to vinyl chloride. J Epidemiol Biostat 1999;4:253-75.

4. Mundt KA, Dell LD, Austin RP, Luippold RS, Noess R, Bigelow C. Historical cohort study of 10109 men in the North American vinyl chloride industry, 1942-72: update of cancer mortality to 31 December 1995. Occup Environ Med 2000; 57:774-81.

5. Ward E, Boffetta P, Andersen A, Colin D, Comba P, Deddens JA, et al. Update of the follow-up of mortality and cancer incidence among European workers employed in the vinyl chloride industry. Epidemiology 2001;12:710-8.

6. Applied Epidemiology Inc. (AEI). Epidemiological study of men employed in the vinyl chloride industry between 1942 and 1972; parts I (Re-analysis of mortality through December 31, 1982) and II (Update of mortality through December 31, 1995): final report prepared for the Vinyl Chloride Panel, Chemical Manufacturers Association. Amherst (MA): AEI; 1999.

7. Ward E, Boffetta P, Andersen A, Colin D, Comba P, Deddens JA, et al. Update of the follow-up of mortality and cancer incidence among European workers employed in the vinyl chloride industry. Lyon: International Agency for Research on Cancer (IARC); 2000. IARC internal report no 00/01.

8. Smulevich VB, Fedotova IV, Filatova VS. Increasing evidence of the rise of cancer in workers exposed to vinylchloride. Br J Ind Med 1988;45:93-7.
9. Laplanche A, Clavel-Chapelon F, Contassot JC, Lanouziere C. Exposure to vinyl chloride monomer: results of a cohort study after a seven year follow up. Br J Ind Med 1992;49: 134-7.

10. Theriault G, Allard P. Cancer mortality of a group of Canadian workers exposed to vinyl chloride monomer. J Occup Med 1981;23:671-6.

11. Weber H, Reinl W, Greiser E. German investigations on morbidity and mortality of workers exposed to vinyl chloride. Environ Health Perspect 1981;41:95-9.

12. Huang M. Epidemiological investigation on occupational malignant tumor in workers exposed to vinyl chloride. In: Ministry of Public Health of China. National epidemiological study on eight occupational cancers (1982-1984) [in Chinese]. Beijing: Ministry of Public Health of China; 1996. p 86-98.

13. Wong R-H, Chen P-C, Du C-L, Wang J-D, Cheng T-J. An increased standardised mortality ratio for liver cancer among polyvinyl chloride workers in Taiwan. Occup Environ Med 2002;59:405-9.

14. Simonato L, L'Abbe KA, Andersen A, Belli S, Comba P, Engholm G, et al. A collaborative study of cancer incidence and mortality among vinyl chloride workers. Scand J Work Environ Health 1991;17:159-69.

15. Fox AJ, Collier PF. Mortality experience of workers exposed to vinyl chloride monomer in the manufacture of polyvinyl chloride in Great Britain. Br J Ind Med 1977;34:1-10.

16. Jones RD, Smith DM, Thomas PG. A mortality study of vinyl chloride monomer workers employed in the United Kingdom in 1940-1974. Scand J Work Environ Health 1988;14:15360.

17. Heldaas SS, Langard SL, Andersen A. Incidence of cancer among vinyl chloride and polyvinyl chloride workers. Br J Ind Med 1984;41:25-30.

18. Langard S, Rosenberg J, Andersen A, Heldaas SS. Incidence of cancer among workers exposed to vinyl chloride in polyvinyl chloride manufacture. Occup Environ Med 2000;57:65-8.

19. Belli S, Bertazzi PA, Comba P, Foa V, Maltoni C, Masina A, et al. A cohort study of vinyl chloride manufacturers in Italy: study design and preliminary results. Cancer Lett 1987; 35:253-61.

20. Pirastu R, Bruno C, De Santis M, Comba P. Indagine epidemiologica sui lavoratori esposti a cloruro di vinile negli stabilimenti di Ferrara, Rosignano e Ravenna [An epidemiologic study of workers exposed to vinyl chloride in the plants of Ferrara, Rosignano and Ravenna]. Epidemiol Prev 1998; 22:226-36.

21. Byren D, Engholm G, Englund A, Westerholm P. Mortality and cancer morbidity in a group of Swedesh VCM and PVC production workers. Environ Health Perspect 1976;17: 167-70.

22. Molina G, Homberg B, Elofsson S, Holmlund L, Moosing R, Westerholm P. Mortality and cancer rates among workers in the Swedish PVC processing industry. Environ Health Perspect 1981;41:145-51.

23. Hagmar L, Akesson B, Nielsen J, Andersson C, Linden K, Attewell R, et al. Mortality and cancer morbidity in workers exposed to low levels of vinyl chloride monomer at a polyvinyl chloride processing plant. Am J Ind Med 1990;17: 553-65.

24. Tabershaw IR, Gaffey WR. Mortality study of workers in the manufacture of vinyl chloride and its polymers. J Occup Med 1974;16:509-18.

25. Cooper WC. Epidemiologic study of vinyl chloride workers: mortality through December 31, 1972. Environ Health 
Perspect 1981;41:101-6.

26. Wong O, Whorton MD, Foliart DR, Ragland D. An industrywide epidemiologic study of vinyl chloride workers, 1942-1982. Am J Ind Med 1991;20:317-34.

27. Dahar WS, Bond GG, McLaren EA, Sabel FL, Lipps TE, Cook RR. Update to vinyl chloride mortality study. J Occup Med 1988;30:648-9.

28. Ott MG, Langer RR, Holder PB. Vinyl chloride exposure in a controlled industrial environment: a long-term mortality experience in 594 employees. Arch Environ Health 1975; 30:333-9.

29. Buffler PA, Wood S, Eifler C, Suarez L, Kilian DJ. Mortality experience of workers in a vinyl chloride monomer production plant. J Occup Med 1979;21:195-203.

30. Wu W, Steenland K, Brown D, Wells V, Jones J, Schulte P, et al. Cohort and case-control analyses of workers exposed to vinyl chloride: an update. J Occup Med 1989;31:518-23.

31. Waxweiler RJ, Stronger W, Wagoner JK, Jones J, Falk H, Carter C. Neoplastic risk among workers exposed to vinyl chloride. Ann N Y Acad Sci 1976;271:40-8.

32. Nicholson WJ, Cuyler Hammond E, Seidman H, Selikoff IJ. Mortality experience of a cohort of vinyl chloride-polyvinyl chloride workers. Ann N Y Acad Sci 1975;246:225-30.

33. Monson RR, Peters JM, Johnson MM. Proportional mortality among vinyl-chloride workers. Lancet 1974;2:397-8.

34. Du CL, Wang JD. Increased morbidity odds ratio of primary liver cancer and cirrhosis of the liver among vinyl chloride monomer workers. Occup Environ Med 1998;55:528-32.

35. DerSimonian R, Laird N. Meta-analysis in clinical trials. Control Clin Trials 1986;7:177-88.

36. Kaczynski J, Hansson G, Wallerstedt S. Incidence of primary liver cancer and aetiological aspects: a study of a defined population from a low-endemicity area. Br J Cancer 1996;73:128-32.

37. Carriaga MT, Henson DE. Liver, gallbladder, extrahepatic bile ducts, and pancreas. Cancer 1995;75 Suppl 1:171-90.

38. L'Abbé KA, Ferro G, Winkelmann R, Saracci R, Simonato L. Mortality and cancer incidence results of the European multicentric cohort study of workers employed in the vinyl chloride industry. Lyon: International Agency for Research on Cancer (IARC); 1989. IARC internal report no 89/007.

39. Checkoway H, Pearce NE, Crawford-Brown DJ. Research methods in occupational epidemiology. New York (NY): Oxford University Press; 1989.

40. Ghandur-Mnaymneh L, Gonzalez MS. Angiosarcoma of the penis with hepatic angiomas in a patient with low vinyl chloride exposure. Cancer 1981;47:1318-24.

41. Williamson IG, Ramsden RT. Angiosarcoma of maxillary antrum-association with vinyl chloride exposure. J Laryngol Otol 1988;102:464-7.

42. Rhomberg W. Exposure to polymeric materials in vascular soft-tissue sarcomas. Arch Occup Environ Health 1998; 71:343-7.

43. International Agency for Research on Cancer (IARC). Report of a working group on epidemiological studies on vinyl chloride exposed people; 1975 Jan 8-9; Lyon. Lyon: IARC; 1975. IARC internal technical report no 75/001.

44. Marion MJ, Boivin-Angele S. Vinyl chloride-specific mutations in humans and animals. In: Singer B, Bartsch H, editors. Exocyclic DNA adducts in mutagenesis and carcinogenesis. Lyon: International Agency for Research on Cancer (IARC); 1999. p 315-24. IARC scientific publications, no 150.

45. Barbin A. Etheno-adduct-forming chemicals: from mutagenicity testing to tumor mutation spectra. Mutat Res 2000;462: $55-69$.

46. Weihrauch M, Lehnert G, Kockerling F, Wittekind C, Tannapfel A. p53 mutation pattern in hepatocellular carcinoma in workers exposed to vinyl chloride. Cancer 2000;88:1030-6.

Received for publication: 18 October 2002 